\title{
Flexible implantable thin film neural electrodes
}

\author{
Sami Myllymaa, Katja Myllymaa and Reijo Lappalainen \\ University of Kuopio, Department of Physics \\ Finland
}

\section{Introduction}

Implantable neural electrodes are widely used tools in basic neuroscience to study the behavior and function of the central nervous system at the tissue and cellular level. There is also a growing interest in the clinical applications of stimulating and recording neural electrodes as well as implantable neural prostheses in which the microelectrodes act as a functional element that connects neurons, i.e. the electrically active cells of the nervous system to the electronic circuitry. Several implantable neural prostheses such as cardiac pacemakers, cochlear implants and deep brain stimulators have been already successfully commercialized. Cochlear implant is a surgically implanted electronic device that utilizes an electrode array inserted into the scala tympani of the cochlea to stimulate the auditory nerve through the bone, enabling the deaf to hear sounds. Deep brain stimulators consist of intracortically implanted electrodes through which a high frequency electrical stimulation is delivered to a targeted region of the brain; they are used in treating several neurological disorders, e.g. Parkinson's disease. Intracranial electrodes consisting of depth electrodes (probes) and subdural electrodes are used to measure local field potentials and occasionally spikes in some clinical cases such as in the presurgical evaluation of patients who are candidates for epilepsy or brain tumor surgery.

Despite the major advances in microsystem technologies and microelectronics, most human neural electrodes are handcrafted from platinum foils and silicone sheet and therefore the devices are quite bulky. Miniaturized electrode arrays with high-channel densities are common in animal models, but their human counterparts are mainly being investigated or at best undergoing clinical trials. Microfabrication techniques, e.g. photolithography and thin film deposition could be useful to obtain multichannel microelectrodes with a high channel density. This would result in a higher spatial resolution which is necessary for accurate recording and stimulation of tiny nervous structures. One major advantage of using well-proven lithographic and thin films techniques is the high reproducibility and the possibility to manufacture many electrodes in a single batch. Additionally modern nanotechnology provides many tools and opportunities to improve the long-term functionality and biocompatibility of implantable electrodes. These include the use of surface modifying thin films of high purity materials and controlled nanotopography and/or microtopography which can be achieved for example by laser ablation techniques. In this chapter, we provide a description of requirements related to implantable electrode materials. And then we discuss the state of the art of the electrodes used in intracranial 
recordings and stimulation, taking into account not only neurophysiological research but also their clinical applications. We will depict the fabrication process and performance of our flexible polyimide-based microelectrodes as a tool for multi-channel cortical surface recordings. We critically review the corresponding other flexible sensor approaches and compare our fabrication methods, material choices and in vivo and in vitro performance of our electrodes to those of other research groups. We will also discuss the future trends and strategies to prolong functional life span and to minimize the immune response to implanted electrodes.

\section{Requirements for materials used in implantable electrodes}

The requirements and demands placed on the materials used in invasive neural electrodes and prostheses are understandingly very high. There are a number of important factors that must be taken into account when selecting materials for electrodes and for the substrate/encapsulation layer to ensure optimal performance and longevity of the neural implant. The ideal neural implant material must be biocompatible without triggering any vigorous local or generalized host response or allergic reactions. The electrode-tissue impedance must be stable and low enough to enable long-term reliable measurements/stimulations. Additionally, the materials should be compatible with magnetic resonance imaging and they should be visible radiographically (Geddes \& Roeder, 2003). In this section, we will discuss these requirements by describing materials typically used particularly concentrating on their electrochemical properties. Biocompatibility aspects will be discussed in section 5 .

\subsection{Electrode materials}

The key function of recording electrodes is to convert the ionic current around the electrode site into electron current. On the other hand, stimulation electrodes deliver the electrical charge to brain tissue aiming to stimulate excitable cells and tissue. Electrodes can be roughly divided into polarizable and non-polarizable electrodes. Ideally polarizable electrode passes current from the electrode to an electrolytic solution by changing the charge distribution within the solution near the electrode. This kind of electrode acts like a capacitor, and only the displacement current crosses the interface. In contrast, ideally a nonpolarizable electrode allows the current to pass freely through the electrode-electrolytic interface without changing the charge distribution in the electrolytic solution.

Two identical bioelectrodes in contact with electrolyte can be modeled in an equivalent circuit model as presented in Fig. 1A. Electrode polarization impedance consists of Warburg (polarization) resistance $R_{w}$ and capacitance $C_{w}$. The Faradic resistance, $R_{f}$ as a parallel with Warburg components, provides a route for direct current to pass through the interface. $R_{s}$ is the resistance of the electrolyte solution. Polarization reactance $\left(X_{w}=1 / 2 \pi f C_{w}\right)$ as well as $R_{w}$ are both frequency dependent: they decrease as $(1 / \sqrt{ } \mathrm{f})$ with increasing frequency. At a sufficient high frequency, the impedance between two electrodes in saline asymptotically approaches the value of $R_{s}$ (Fig. 1B). $R_{w}, C_{w}$ and $R_{f}$ are also dependent on the geometry of the electrode material, electrode size and current density.

A silver-silver chloride electrode $(\mathrm{Ag} / \mathrm{AgCl})$ is almost perfectly non-polarizable, has a small and stable offset potential and therefore is widely utilized as the surface (skin) biopotential electrode, but it cannot be used as an implantable electrode because of the rapid dissolution 

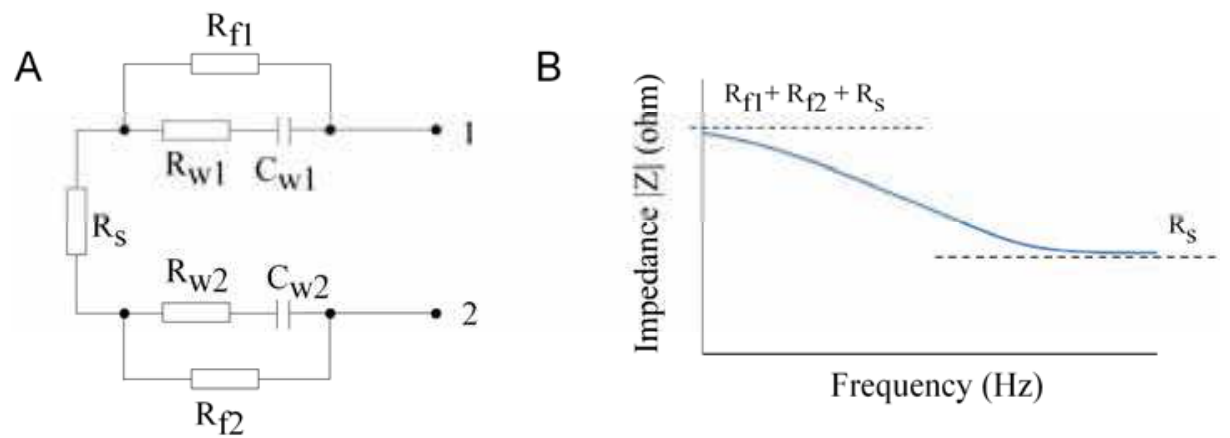

Fig. 1. (A) The equivalent circuit model for a two identical bioelectrodes immersed in saline. (B) Typical electrode-electrolyte impedance graph measured between the terminals 1 and 2 as a function of frequency

of silver. Furthermore, $\mathrm{AgCl}$ as well as pure $\mathrm{Ag}$ has a toxic effect on neural tissue (Yuen et al., 1987). Noble metals such as platinum (Pt), gold ( $\mathrm{Au}$ ) and iridium (Ir) have been the most commonly used electrode materials in neural prosthetic applications due to their excellent corrosion resistance and biocompatibility properties (Geddes \& Roeder, 2003). They are highly polarizable electrodes meaning that the ionic current in tissue can give rise to an electric current in the metal electrode, and almost no charge carriers pass through the interface. Current densities for recording purposes are so low that the interface has a linear current-voltage relationship. If one wishes stimulation, then higher current densities are required to elicit neural excitation reactions resulting in Faradaic current flow, in which charge carriers pass through the interface. Irreversible electrochemical reactions can occur and change the chemical composition of the electrode-electrolyte interface. The limit for a maximum reversible charge injection depends on the electrode material as well as its shape, size and the stimulation waveform.

$\mathrm{Pt}$ is clinically utilized as an electrode material in various neural applications such as in cardiac pacemakers, cochlear implants and subdural strip and grid electrodes. Pt suffers from corrosion only slightly in both recording and stimulating use. Pt is commonly used as an inert reference electrode in electrochemistry since it is at the extreme of the galvanic series. Au is often used in recording electrodes but it suffers from corrosion if used for stimulating purposes. On the contrary, Ir is mainly utilized as a stimulating electrode. The electrode properties of Ir can be further developed by electrochemical activation that leads to the adhesion of a porous and very stable oxide layer on the electrode surface. The property of enhanced corrosion resistance of activated iridium oxide (AIROF) is particularly important in stimulating electrodes to avoid metal dissolution during electric pulsing. The AIROF has a high charge delivery capacity and therefore it is well suited for use in stimulating electrodes. Activation also reduces the electrode impedance due to the porosity. Another new potential electrode candidate for use in stimulating electrodes is titanium nitride (TiN). The high charge delivery capacity of TiN is based on its high effective surface area due to the columnar structure of this material. TiN is already being clinically utilized in pacemakers. Optically transparent indium tin oxide (ITO) is an extensively employed electrode material used in electrochemistry, but at present its use in neurophysiology is virtually limited to in vitro microelectrode arrays for recording electrical signals from 
neurons. The compatibility of ITO for chronic in vivo recording is not completely understood although recent investigations have shown promising results in terms of cell adhesion and proliferation (Bogner et al., 2006) as well as protein adsorption (Selvakumaran et al., 2008). Correspondingly, the electrically conductive hard ceramic, glassy carbon is an extensively applied electrode material in electroanalytical chemistry, but it is rarely used as an implantable electrode.

\subsection{Substrate and encapsulation materials}

The substrate and encapsulation materials need to be biocompatible, biostable and possess good dielectric properties. Good biocompatibility means that material must not evoke a toxic, allergic or immunologic reaction. Biostability means that the implant material must not be susceptible to attack by biological fluids or any metabolic substances. The surface area of substrate/encapsulation material is much larger compared to areas of the active electrode sites. Therefore substrate and insulator materials have an important role in longterm stability and functioning of neural implants.

A substrate material that has been widely utilized for neural interfaces in the central nervous system is silicon $(\mathrm{Si})$. Silicon dioxide $\left(\mathrm{SiO}_{2}\right)$ and silicon nitride $\left(\mathrm{Si}_{3} \mathrm{~N}_{4}\right)$ are typical insulators used with silicon base. However, there is a mismatch between the mechanical properties of the soft brain tissue and the rigid silicon and thus causes many adverse effects such as tissue damage, inflammatory reactions and scar formation (Polikov et al., 2005). Therefore, there has been a growing interest toward developing polymer-based implant materials that could be flexible enough to mimic biological tissue and to reduce mechanical damage but not evoking any adverse tissue reactions. Additionally, their composition and surface properties can be modified in a variety of ways to make by them more biocompatible. Polymers can be employed as both substrate and/or encapsulation materials. Different flexible polymer materials such as polyimide, benzocyclobutene (BCB), polydimethylsiloxane (PDMS), parylene and epoxy resins have been recently investigated as substrate/encapsulating materials in implantable neural interfaces (Cheung, 2007). Polyimide has been used as an insulator in microelectronics because of its numerous excellent properties: excellent resistance to solvents, strong adhesion to metals and metal oxides and good dielectric properties. The volume resistivity and dielectric strength of polyimide are comparable to silicon and typical silicon insulation materials, such as $\mathrm{SiO}_{2}$ and $\mathrm{Si}_{3} \mathrm{~N}_{4}$ (Stieglitz et al., 2000). When used as a neural implant material, polyimide has also appropriate mechanical properties and its biocompatibility has been demonstrated in many studies in vitro and in vivo (Stieglitz et al., 2000; Richardson et al., 1993). Table 1 summarizes some important properties of polyimide and PDMS in comparison to $\mathrm{Si}$ and $\mathrm{SiO}_{2}$. The major disadvantage of polyimide is its permeability to environmental moisture and ions that could be crucial in terms of short circuiting and reducing the electrode's life span. BCB has been a widely used material in microelectronics due to its low moisture absorption, good dielectric properties and chemical stability. Recently BCB has been demonstrated to be a potential material for use in implantable neural interfaces (Lee et al., 2004a). Parylene and silicone rubber (PDMS) are known to be biocompatible materials and they are approved for use as an implanted material in medical devices (i.e. FDA approved). Parylene is a thermoplastic polymer that can be vapor-deposited at room temperature to form pin-hole free barrier coatings that are stress-free, chemically and biologically inert and stable as well as being 
minimally permeable to moisture. Paralyne as well as PDMS are both hydrophobic and optically transparent materials and thus they can be used in optical elements.

\begin{tabular}{|l|l|l|l|l|l|}
\hline & \multicolumn{1}{|c|}{ Units } & \multicolumn{1}{|c|}{ PDMS } & \multicolumn{1}{|c|}{ Polyimide } & \multicolumn{1}{|c|}{ Silicon } & Silicon dioxide \\
\hline Tensile strength & $\mathrm{kg} / \mathrm{mm}^{2}$ & $0.4-1.1$ & 13.5 & 1225 & $5-14$ \\
\hline Elongation & $\%$ & 140 & 15 & - & - \\
\hline Density & $\mathrm{g} / \mathrm{cm}^{3}$ & 1.11 & 1.45 & 2.1 & 2.3 \\
\hline Young's modulus & $\mathrm{kg} / \mathrm{mm}^{2}$ & $0.04-0.09$ & 245 & $20 \cdot 10^{3}$ & $7 \cdot 10^{3}$ \\
\hline $\begin{array}{l}\text { Dielectric constant } \\
\text { at } 1 \mathrm{kHz}, 50 \% \mathrm{RH}\end{array}$ & $\begin{array}{l}\text { relative } \\
\left(\varepsilon_{\mathrm{r}}\right)\end{array}$ & 2.70 & 3.3 & 12 & 3.9 \\
\hline $\begin{array}{l}\text { Dielectric strength } \\
\text { at } 1 \mathrm{KHz}, 50 \% \mathrm{RH}\end{array}$ & $\mathrm{V} / \mathrm{cm}$ & $1.4 \cdot 10^{5}$ & $2 \cdot 10^{6}$ & $3 \cdot 10^{5}$ & $6 \cdot 10^{6}$ \\
\hline $\begin{array}{l}\text { Volume resistivity } \\
\text { nolume }\end{array}$ & $\Omega \cdot \mathrm{cm}$ & $2.9 \cdot 10^{14}$ & $10^{16}$ & - & $10^{16}$ \\
\hline
\end{tabular}

Table 1. Some physical properties of PDMS (Sylgard 184, Dow Corning Inc.) and polyimide (Pyralin PI 2525, HD Microsystems GmbH) in comparison to silicon and silicon dioxide. Values are taken from the datasheets for Sylgard 184 (Dow Corning Inc.) and for Pyralin PI 2525 (HD Microsystems $\mathrm{GmbH}$ ) and from Stieglitz et al., 2000; Mata et al., 2005; Armani et al., 1999

\section{Recent recording and stimulating brain electrodes in clinical use}

Human electroencephalography (EEG) recordings are typically performed with different numbers of electrodes attached to the scalp and measuring the potential differences between electrodes. However, source localization of scalp-EEG is rather poor. To achieve better spatial resolution, it is advantageous to place the electrodes closer to the brain tissue. Both penetrating (intracortical) electrode probes and non-penetrating electrode arrays placed on the surface of cerebellum cortex have been utilized to measure neuronal action potentials and local field potentials from the brain. Compared to human scalp-EEG, intracranial recordings are advantageous in terms of increased spatial resolution, signal amplitude level and reduced noise level meaning that one can acquire more detailed maps directly of brain. However, the use of penetrating electrode probes in humans is limited to the areas destined for surgical resection because of the risk of damaging the brain tissue, whereas flexible subdural strip and grid electrodes placed on the surface of cortex are used as a less invasive method in some clinical cases, e.g. in mapping cerebellum cortex in patients undergoing epilepsy or brain tumor surgery. The signals recorded with subdural electrodes are considerably higher in amplitude because they are much closer to the source of the activity, and are separated from it by only a relatively high conductivity media (CSF, brain parenchyma). Subdural electrodes are virtually free of artifacts (e.g. not affected by electrical signals originating from muscles) that are seen in scalp-EEG, and thus they yield a much higher signal-to-noise ratio (Nair et al., 2008). Typical commercially available subdural strip and grid electrodes consist of stainless steel or platinum foil contacts with exposed diameter of about 2-3 mm embedded in flexible biomedical-grade silicone plates (e.g., AD Tech 
Medical Instrument Corp., Racine, WI, USA; PMT Corp. Chanhassen, MN, USA). Epidurally implanted surface electrodes as well as penetrating intracortical probes are also utilized for stimulating purposes in humans. Motor cortex stimulation (MCS) is a relative new technique in which surface electrodes are used at low current densities to stimulate the motor area (Brodman 4) in treating chronic neuropathic pain (Rasche et al., 2006). Deep brain stimulators consist of intracortically implanted electrodes through which a high frequency electrical stimulation is delivered to targeted regions of the brain, for example being used in treating severe neurological disorders, e.g. in Parkinson's disease.

Although modern microfabrication techniques possess a great potential to develop novel high-density microelectrode arrays for recording of brain activity or electrical stimulation of neural tissue, and these kinds of microarrays are extensively utilized in animal studies, no microelectrode array suitable for use with human patients is on the market today. For example, different lithographic and thin film techniques could be utilized in the development of substrate-integrated electrodes with higher spatial resolution than the present subdural electrodes in clinical use.

\section{Microelectrode arrays in animal models}

Neurophysiologists have traditionally performed chronic cortical recordings in animal models with insulated microwires and wire bundles (Nicolelis et al., 1997; Williams et al., 1999). The first chronic recordings from freely moving animals with stainless steel microwire electrodes were performed in the 1950s (Strumwasser, 1958). The development of photolithographic, silicon etching and thin-film deposition techniques provided novel approaches in the development of improved recording and stimulating systems used in experiments with animal models (Wise, 2005). Silicon has been the most widely used substrate material because of the well-established precise microfabrication methods which have been developed for integrated circuits. The main advantage of microfabricated electrode arrays compared to microwire bundles is the precise control of the electrode sizes and the separations between electrodes. Batch-processing also means that there can be large volume and low-cost production of identical microsensors. Michigan probes (Najafi \& Wise, 1986) and Utah arrays (Campbell et al., 1991) are perhaps the best-known Si-based microelectrodes. The typical Michigan arrays are single-shank or multi-shank Si penetrating probes where the electrodes are placed along the length of the shank allowing the measurement of neuronal activity at various depths of the brain tissue. The threedimensional Utah array consists of 100 conductive Si needles (length $1.5 \mathrm{~mm}$ ) with platinum coated tips. However, due to mechanical mismatch between the rigid Si (Young's modulus $\sim 170 \mathrm{GPa})$ and soft brain tissue $(\sim 3 \mathrm{kPa})$ and subsequent adverse tissue responses, there has been a growing interest in developing polymer-based implants that could be flexible enough to mimic biological tissue and to reduce adverse tissue reactions.

\subsection{Flexible polymer-based microelectrode arrays}

Different flexible polymer materials such as polyimide, BCB, PDMS, parylene-C and epoxy resins have been recently investigated as substrate materials in implantable neural interfaces (Cheung, 2007). These polymers are also utilized in coating silicon-based implants providing both a chemical barrier and an electrical insulation layer. The flexibility of the polymer may decrease the mismatch between the mechanical properties of nervous tissue and the rigid 
implant and thus reduce the risk of tissue damage and inflammation reactions due to electrode micromotion.

Several polyimide-based microelectrode arrays (MEA), i.e. polyimide-metal-polyimide sandwich structures have been developed in the field of neural engineering for various applications (Cheung, 2007). Typically these approaches utilize polyimide as a base material with a thickness of a few tens of micrometers. A thin film of suitable electrode material, such as $\mathrm{Au}, \mathrm{Pt}$ or Ir is coated on the top of polyimide by using physical vapour deposition techniques, e.g. sputtering or evaporation, and then they are structured photolithographically. A thin layer (a few micrometers) of insulating material is structured on the top of the metallization layer leaving the desired areas (i.e. electrode sites) open, whereas the interconnecting lines are completely covered to avoid short-circuits in a moist environment containing salt ions. These kinds of flexible microelectrode arrays have been developed for studying brain slices in vitro (Boppart et al., 1992), cortical surface field potential recordings (Owens et al., 1995; Hollenberg et al., 2006; Takahashi et al., 2003; Myllymaa et al., 2008b; 2009) and intracortical multiunit neural activity recordings (Rousche et al., 2001; Cheung et al., 2007; Mercanzini et al., 2008) and for action potential recording in nerve and muscle tissues in vivo (González \& Rodríguez 1997; Rodríguez et al., 2000; Spence et al., 2007). Stieglitz et al. have also fabricated different kinds of polyimide-based microdevices (e.g. sieve and cuff electrodes) for interfacing with regenerating peripheral nerves (Stieglitz et al., 2000; Stieglitz et al., 1997; 2001). Some recently published papers focusing on the development of polymer-based neural microelectrodes for recording brain activity and stimulating the brain tissue are summarized in Table 2.

\begin{tabular}{|c|c|c|c|c|c|}
\hline reference & $\begin{array}{l}\text { substrate }(S) / \\
\text { insulator }(\mathrm{I}) \\
\text { material and } \\
\text { their } \\
\text { thicknesses } \\
\end{array}$ & $\begin{array}{l}\text { electrode } \\
\text { material and } \\
\text { its deposition } \\
\text { method }\end{array}$ & $\begin{array}{l}\text { electrode size } \\
\text { and number } \\
\text { of electrodes }\end{array}$ & $\begin{array}{l}\text { electrode } \\
\text { impedance } \\
\text { measured } \\
\text { in vitro at } 1 \\
\mathrm{kHz} \\
\end{array}$ & $\begin{array}{l}\text { application } \\
\text { (performed in } \\
\text { vivo studies) }\end{array}$ \\
\hline $\begin{array}{l}\text { Owens et } \\
\text { al., } 1995\end{array}$ & $\begin{array}{l}\text { S: polyimide } \\
2 \mu \mathrm{m} \\
\text { I: polyimide } \\
2 \mu \mathrm{m}\end{array}$ & $\begin{array}{l}\text { evaporated } \\
\mathrm{Cr}(15 \mathrm{~nm})+ \\
\text { Au }(300 \mathrm{~nm})+ \\
\text { electroplated } \\
\text { Pt black }\end{array}$ & $\begin{array}{l}40 \times 40 \mu \mathrm{m}^{2} \\
24 \text { electrodes } \\
\text { (lithographic } \\
\text { patterning) }\end{array}$ & $11-16 \mathrm{k} \Omega$ & $\begin{array}{l}\text { acute evoked } \\
\text { potential } \\
\text { recording from } \\
\text { the surface of } \\
\text { ferret cortex }\end{array}$ \\
\hline $\begin{array}{l}\text { Rousche } \\
\text { et al., } 2001\end{array}$ & $\begin{array}{l}\text { S: polyimide } \\
10 \mu \mathrm{m} \\
\text { I: polyimide } \\
10 \mu \mathrm{m}\end{array}$ & $\begin{array}{l}\text { evaporated } \\
\mathrm{Cr}(25 \mathrm{~nm})+ \\
\mathrm{Au}(200 \mathrm{~nm})\end{array}$ & $\begin{array}{l}30 \times 30 \mu \mathrm{m}^{2} \\
\text { (lithographic } \\
\text { patterning) }\end{array}$ & $\begin{array}{l}1837 \pm \\
197.3 \mathrm{k} \Omega\end{array}$ & $\begin{array}{l}\text { intracortical } \\
\text { recording with } \\
\text { bioactive } \\
\text { capability }\end{array}$ \\
\hline $\begin{array}{l}\text { Takahashi } \\
\text { et al., } 2003\end{array}$ & $\begin{array}{l}\text { S: polyimide } \\
25 \mu \mathrm{m} \\
\text { I: polyimide } \\
<1 \mu \mathrm{m}\end{array}$ & $\begin{array}{l}\mathrm{Cr}(\text { thin })+ \\
\mathrm{Au}(200 \mathrm{~nm})\end{array}$ & $\begin{array}{l}80 \times 80 \mu \mathrm{m}^{2} \\
69 \text { electrodes } \\
\text { (lithographic } \\
\text { patterning) }\end{array}$ & $330 \pm 65 \mathrm{k} \Omega$ & $\begin{array}{l}\text { acute evoked } \\
\text { potential } \\
\text { recording from } \\
\text { the surface of } \\
\text { rat cortex }\end{array}$ \\
\hline $\begin{array}{l}\text { Lee et al., } \\
2004 b\end{array}$ & $\begin{array}{l}\text { S: BCB } 10 \mu \mathrm{m} \\
\text { I: BCB } 10 \mu \mathrm{m}\end{array}$ & $\mathrm{Au}(200 \mathrm{~nm})$ & $\begin{array}{l}20 \times 20 \mu \mathrm{m}^{2} \\
3 \text { electrodes } \\
\text { (lithographic } \\
\text { patterning) }\end{array}$ & $\sim 1200 \mathrm{k} \Omega$ & $\begin{array}{l}\text { intracortical } \\
\text { recording with } \\
\text { micro-fluidic } \\
\text { channels }\end{array}$ \\
\hline
\end{tabular}




\begin{tabular}{|c|c|c|c|c|c|}
\hline $\begin{array}{l}\text { Takeuchi } \\
\text { et al., } 2005\end{array}$ & $\begin{array}{l}\text { S: parylene } \\
5 \mu \mathrm{m} \\
\text { I: parylene } \\
5 \mu \mathrm{m}\end{array}$ & $\mathrm{Au}(1 \mu \mathrm{m})$ & $\begin{array}{l}\text { different } \\
\text { geometries } \\
\text { and numbers } \\
\text { of electrodes }\end{array}$ & $\begin{array}{l}\sim 100 \mathrm{k} \Omega \\
\text { (single } \mathrm{Au} \\
\text { electrode } \\
\text { inside the } \\
\text { channel) }\end{array}$ & $\begin{array}{l}\text { intracortical } \\
\text { recording with } \\
\text { micro-fluidic } \\
\text { channels }\end{array}$ \\
\hline $\begin{array}{l}\text { Kitzmiller } \\
\text { et al., } 2006\end{array}$ & PDMS & $\begin{array}{l}\text { evaporated } \\
\mathrm{Pt}(200 \mathrm{~nm})\end{array}$ & $\begin{array}{l}200 \times 200 \mu \mathrm{m}^{2} \\
8 \text { electrodes } \\
\text { (lithographic } \\
\text { patterning) }\end{array}$ & $\begin{array}{l}\text { not } \\
\text { mentioned }\end{array}$ & $\begin{array}{l}\text { acute evoked } \\
\text { potential } \\
\text { recording from } \\
\text { the surface of } \\
\text { pig cortex }\end{array}$ \\
\hline $\begin{array}{l}\text { Hollenberg } \\
\text { et al., 2006; } \\
\text { Yeager et } \\
\text { al., } 2008\end{array}$ & $\begin{array}{l}\text { S: polyimide } \\
25 / 50 \mu \mathrm{m} \\
\text { I: SU- } 8 \text { epoxy } \\
13 \mu \mathrm{m}\end{array}$ & $\begin{array}{l}\text { sputtered } \\
\text { Ti-W }(5 \mathrm{~nm})+ \\
\mathrm{Au}(300 \mathrm{~nm})\end{array}$ & $\begin{array}{l}\text { Ǿ: } 150 \mu \mathrm{m} \\
\text { (round) } \\
64 \text { electrodes } \\
\text { (lithographic } \\
\text { patterning) }\end{array}$ & $225 \pm 90 \mathrm{k} \Omega$ & $\begin{array}{l}\text { acute and } \\
\text { chronic evoked } \\
\text { potential } \\
\text { recording from } \\
\text { the surface of } \\
\text { rat cortex }\end{array}$ \\
\hline $\begin{array}{l}\text { Molina- } \\
\text { Luna et al., } \\
2007 ; \\
\text { Hosp et al., } \\
2008\end{array}$ & $\begin{array}{l}\text { S: polyimide } \\
7 \mu \mathrm{m} \\
\text { I: polyimide } \\
7 \mu \mathrm{m}\end{array}$ & $\begin{array}{l}\mathrm{Ti}(10 \mathrm{~nm})+ \\
\mathrm{Au}(300 \mathrm{~nm})+ \\
\mathrm{TiN}(800 \mathrm{~nm})\end{array}$ & $\begin{array}{l}\text { Ǿ: } 100 \mu \mathrm{m} \\
\text { (round) } \\
72 \text { electrodes } \\
\text { (lithographic } \\
\text { patterning) }\end{array}$ & $5-10 \mathrm{k} \Omega$ & $\begin{array}{l}\text { epidural } \\
\text { stimulation } \\
\text { mapping of rat } \\
\text { motor cortex }\end{array}$ \\
\hline $\begin{array}{l}\text { Cheung et } \\
\text { al., 2007; } \\
\text { Mercanzini } \\
\text { et al., } 2008\end{array}$ & $\begin{array}{l}\text { S: polyimide } \\
20 \mu \mathrm{m} \\
\mathrm{I}: \text { polyimide } \\
1.5 \mu \mathrm{m}+1.5 \\
\mu \mathrm{m}\end{array}$ & $\begin{array}{l}\text { sputtered } \\
\mathrm{Ti}(50 \mathrm{~nm})+ \\
\mathrm{Pt}(200 \mathrm{~nm})\end{array}$ & $\begin{array}{l}\text { Ǿ: } 25 \mu \mathrm{m} \\
\text { (round) } \\
16 \text { electrodes } \\
\text { (in two layers) }\end{array}$ & $\sim 1000 \mathrm{k} \Omega$ & $\begin{array}{l}\text { acute and } \\
\text { chronic } \\
\text { intracortical } \\
\text { recordings into } \\
\text { the rat cortex }\end{array}$ \\
\hline $\begin{array}{l}\text { Myllymaa et } \\
\text { al., 2008b; } \\
2009\end{array}$ & $\begin{array}{l}\text { S: polyimide } \\
30 \mu \mathrm{m} \\
\text { I: polyimide } \\
3 \mu \mathrm{m}\end{array}$ & $\begin{array}{l}\text { sputtered } \\
\mathrm{Ti}(20 \mathrm{~nm})+ \\
\mathrm{Pt}(200 \mathrm{~nm})\end{array}$ & $\begin{array}{l}\text { Ǿ: } 100-200 \mu \mathrm{m} \\
\text { (round) } \\
8-16 \\
\text { electrodes } \\
\text { (lithographic } \\
\text { patterning) }\end{array}$ & $25.5 \pm 2.0 \mathrm{k} \Omega$ & $\begin{array}{l}\text { acute and } \\
\text { chronic } \\
\text { recording } \\
\text { evoked } \\
\text { potentials from } \\
\text { the surface of } \\
\text { rat cortex }\end{array}$ \\
\hline
\end{tabular}

Table 2. Microfabricated polymer-based neural electrodes for recording brain activity and stimulating brain tissue (summary of recent publications)

\subsection{Development of microelectrode arrays (MEA) for cortical surface recordings}

Our sensor research is focused on the development of polymer-based thin film electrodes and electrode arrays which can be used for recording of biosignals as well as for stimulation of excitable tissue. The fabrication and testing of flexible microelectrode array that is suitable for multichannel cortical surface recordings in rats is described in detail elsewhere (Myllymaa et al., 2008b; 2009). Here we discuss the major aspects of the development and fabrication process as well as the results from in vitro and in vivo testing. The fabrication process was developed and iterated to a fully functional solution during a two year trial period when suitable substrate material, substrate thickness, electrode material, sensor layout and insulation material were optimized (Myllymaa et al., 2008a). 


\subsubsection{Array fabrication}

The fabrication process of the microelectrode array is based on creating magnetron sputter deposited (AJA Inc., Stiletto Serie ST20I), lithographically patterned stable Pt thin films between two biocompatible polyimide layers. The fabrication steps of arrays are schematically illustrated in Fig. 2. The fabrication was implemented on top of microscope glass slides, 2" $\times 3$ 3" (Logitech), to guarantee a rigid support during fabrication. As a base layer we used a $25 \mu \mathrm{m}$ thick Kapton HN film (DuPont) together with spin coated Pyralin PI 2525 (HD Microsystems $\mathrm{GmbH}$ ) polyimide layer (Fig. 2A). A negative photoresist (ma-N 1420, Micro resist technology $\mathrm{GmbH}$ ) was spun on the base layer and patterned using 365 $\mathrm{nm}$ UV exposure and wet developer chemicals (Fig. 2B). Thin films of Ti $(20 \mathrm{~nm})$ and $\mathrm{Pt}(200$ $\mathrm{nm}$ ) were DC sputtered onto a surface of the base layer (Fig. 2C) and structured with a liftoff technique (Fig. 2D). Ti was used beneath the Pt to improve the adhesion between the polyimide and the metal layer. Then, photosensitive polyimide PI-2771 (HD Microsystems $\mathrm{GmbH}$ ) was spin coated on an array pattern (Fig. 2E) and patterned with alignment of metallization layer. About a $3 \mu \mathrm{m}$ thick insulation layer was formed on all positions except for the areas of the electrodes and connection pads (Fig. 2F). Finally, the array was detached from the glass slide (Fig. 2G).

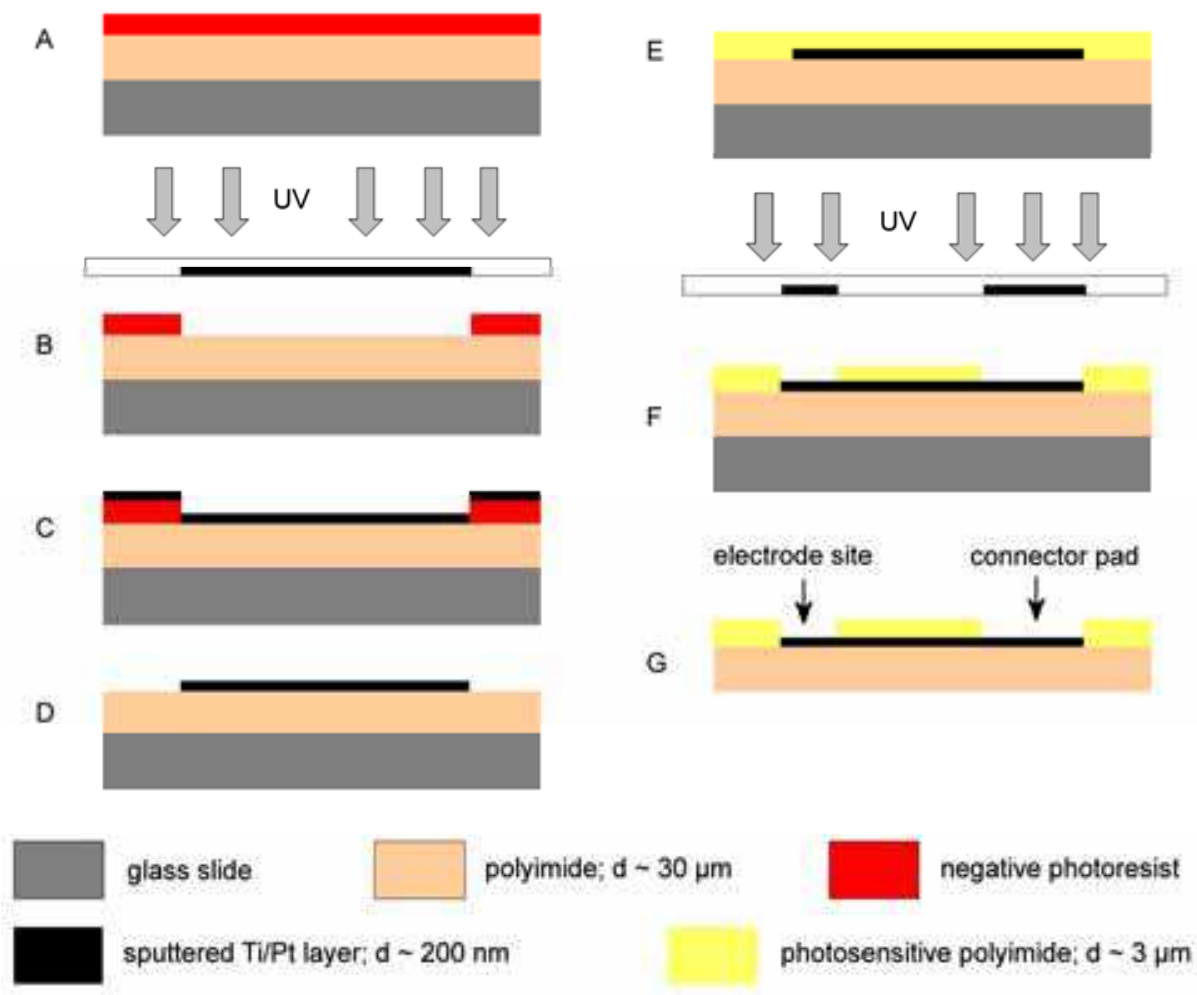

Fig. 2. Fabrication steps of flexible microelectrode arrays. See details in the text 
The developed arrays consisted of either 8 or 16 round-shaped Pt-electrodes (round, $\varnothing 100$ $200 \mu \mathrm{m}$ ) in an area of about $2 \mathrm{~mm} \times 2 \mathrm{~mm}$ at the end of polyimide ribbon. Thin film connector pads at one of the edges of polyimide foil were designed to fit into a 16-channel $0.5 \mathrm{~mm}$ pitch zero-insertion-force (ZIF) connector (JST Ltd., Halesworth, UK). The ZIF connector was soldered to a thin $(0.2 \mathrm{~mm})$ printed circuit board (PCB) adapter. The PCB contains also a 16-channel surface mount microsocket (CLM-serie, Samtec Inc., New Albany, IN, USA) through which the electrical signals from the electrodes are transferred to the preamplifier and further to the recording instrumentation. The prototype of flexible microelectrode array with connector board as well as a schematic view of the array crosssection is shown in Fig. 3.
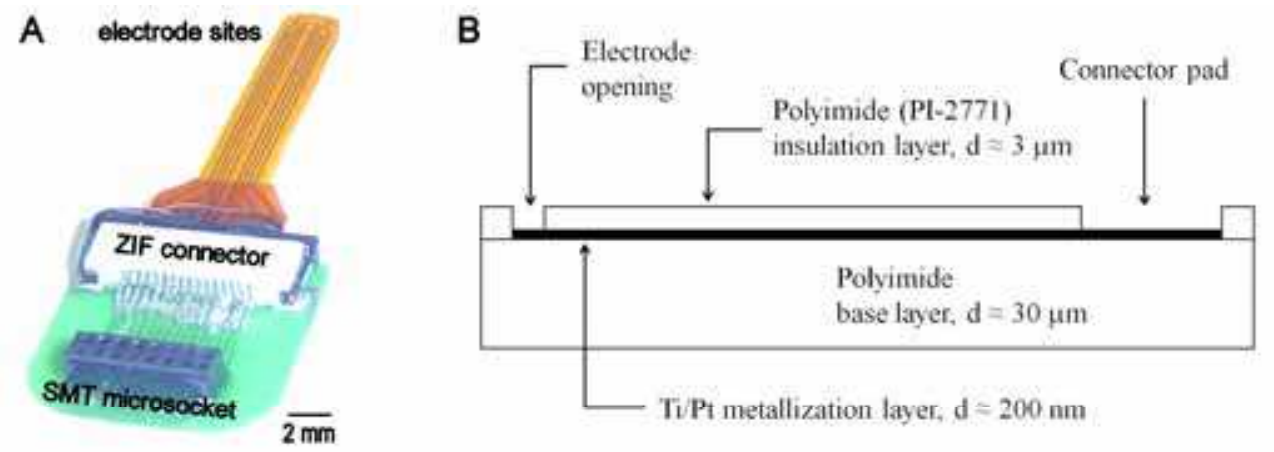

Fig. 3. (A) The developed microelectrode array. The array is connected via a printed circuit board consisting of a ZIF type connector and a SMT microsocket to the recording instrumentation. (B) A schematic illustration of the array cross-section (not to scale, d: thickness)

The use of non-photosensitive polyimide as an insulation layer has been very common in neural interfaces (González \& Rodríguez 1997; Cheung et al., 2007; Mercanzini et al., 2008). In contrast, the fabrication process described above utilizes photosensitive polyimide grade that remarkably simplifies the array fabrication i.e. it can be patterned directly by UV exposure and developer chemicals. Thus, no photoresist and/or hard mask as an etch template is needed as is the case with standard non-photosensitive polyimides. Aluminum is a commonly used hard mask material in polyimide dry etching. It is possible that aluminum residuals may remain on the final device after the fabrication process and further come into contact with neural tissue and these ions can be very toxic and cause adverse tissue reactions (Wennberg, 1994). This risk can be eliminated by using photosensitive polyimide. The SEM images (Fig 4) demonstrate that it is possible to pattern the photosensitive polyimide (PI-2771) layer with an almost vertical edge profile without any residuals.

While the excellent biocompatibility of polyimide has been proven in many studies (Richardson et al., 1993; Stieglitz et al., 2000; Seo et al., 2004), these exists only one report focusing on the assessment of cytotoxicy of photosensitive polyimide grade (Sun et al., 2008) involving different chemistry and solvent processes. Therefore, further investigations are 
needed to ensure the biocompatibility of photosensitive polyimide grades that there will be no adverse, long term effects and that the material is suitable for chronic implantable use.
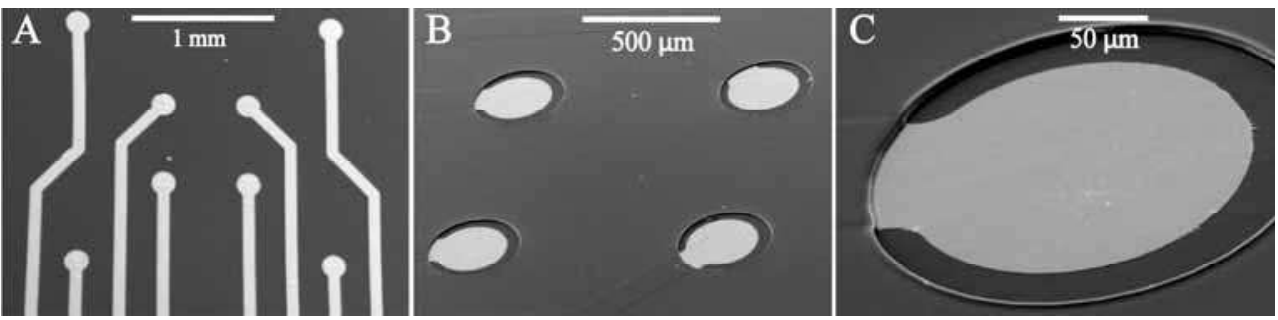

Fig. 4. SEM-image of $\mathrm{Ti} / \mathrm{Pt}$ metallization layer viewed at the end of recording sites $(\mathrm{A})$ and electrode opening(s) at two magnifications (B-C). A thin insulating layer (photosensitive polyimide) is patterned with alignment of the metallization layer

\subsubsection{Electrochemical characterization}

Electrochemical impedance spectroscopy (EIS) is a commonly used method to characterize the electrochemical properties of microelectrodes, i.e. to assess the recording capabilities of the electrode for neural recording experiments. In a typical two electrode cell system, the microelectrode is immersed in physiological saline solution $(0.9 \% \mathrm{NaCl})$ and a small sinusoidal perturbation voltage $(5-50 \mathrm{mV})$ is applied between the microelectrode and the counter electrode (typically a noble metal, e.g. Pt) having a much larger surface area. A small perturbation voltage is needed to ensure that a linear current-voltage response is obtained at each frequency. Measurements are usually taken over a wide frequency region (e.g. $0.1 \mathrm{~Hz}-100 \mathrm{kHz}$ ) at room temperature. The induced current and its phase are recorded. Typical impedance spectra, measured with a Solartron 1260 impedance gain/phase analyzer (Solartron Analytical, Farnborough, UK) for Pt and Au microelectrodes with diameter of $200 \mu \mathrm{m}$ is presented in Fig. 5.
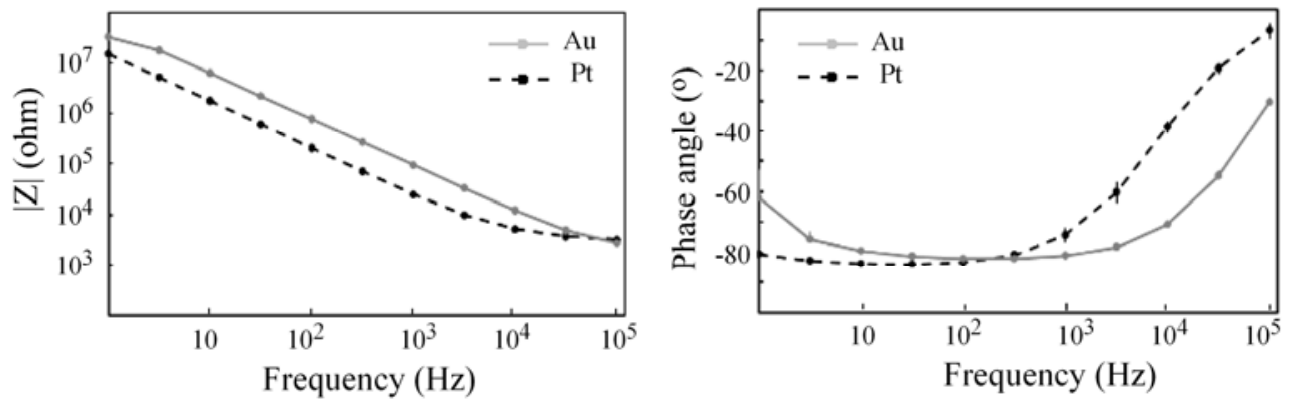

Fig. 5. Impedance magnitude and phase for $\mathrm{Pt}$ and $\mathrm{Au}$ microelectrodes with a diameter of $200 \mu \mathrm{m}$

The EIS results demonstrated that our microelectrodes possessed suitable electrochemical properties for neural recordings. Pt has a much lower impedance level compared to $\mathrm{Au}$ especially at low frequencies (below $1 \mathrm{kHz}$ ) which are the most relevant in any recordings of cortical signals. 


\subsubsection{In vivo testing}

The performance of our microelectrode arrays was tested in acute and chronic recordings in Wistar rats. All animal tests were conducted in accordance with the Council of Europe guidelines and approved by the Institutional Animal Care and Use committee and the State Provincial Office of Eastern Finland.

During the recording sessions, the signals from the electrodes was passed through a preamplifier (Neuralynx Inc., Bozeman, MT, USA) and led into the main amplifier (Grass Instruments, West Warwick, RI, USA) with the data acquisition PC running DataWave SciWorks. Both electrical current and auditory stimuli were used. The square wave current stimuli were of $1 \mathrm{~ms}$ duration, and the stimuli of auditory were $10 \mathrm{~ms}$ in duration, generated by a WPI (Aston, Stevenage, Herts, UK) isolated current source and led into a piezo buzzer on the front paw of the rat. A stimulus set consisted of paired pulses (a gating paradigm) and the trials were averaged in sets of 25 .

Wistar rats were anesthetized with $1.2-1.5 \mathrm{~g} / \mathrm{kg}$ urethane for acute recordings and with a mixture of $0.5 \mathrm{mg} / \mathrm{kg}$ medetomidine (Domitor) and $75 \mathrm{mg} / \mathrm{kg}$ ketamine (Ketalar) intraperitoneally for implantation for chronic recordings. The rats were placed in a stereotaxic apparatus. Holes for the microelectrode array and for reference electrodes were drilled on the same side of the skull. The microelectrode array was inserted on the dura over the parietal cortex. A stainless steel (SS) screw was used as a reference (ground) electrode placed at A 1.0, L 1.0 with respect to bregma, i.e. 2-3 mm in front of bregma. SS screws also acted as an anchor when the array was cemented onto the skull in the chronic recordings. After anesthesia, the rat was aroused by administration of the antagonist atimepazole (Antisedan), after the surgery. The rats were allowed to recover for a minimum of 7 days before the first experiments. In the chronic recordings, the implanted rat was connected to the recording apparatus and it was either allowed to move freely in the recording box or was gently immobilized by holding it securely in a towel.

The arrays demonstrated excellent flexibility and mechanical strength during handling and implantation onto the surface of rat cortex. During the acute recording session, the microelectrode array was capable of yielding stable readings as observed in the form of the standard response parameters, such as latencies, onsets and decays of the main components in the voltage traces. An example of the somatosensory evoked potential (SEP) recording, obtained 4 hours after the onset of anesthesia is presented in Fig. 6. 


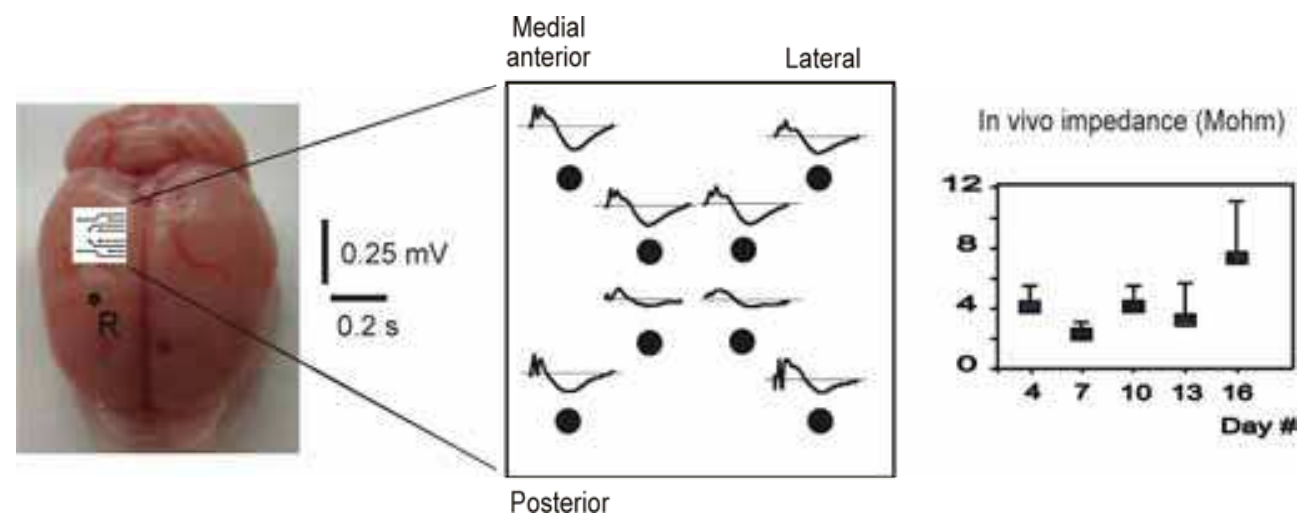

Fig. 6. An example of the in vivo somatosensory evoked potential recording in the rat parietal cortex. Profiles of averaged evoked potentials using the 8-channel MEA are shown above the corresponding recording site (black dots). The current stimuli were delivered to the left paw of the rat. The position of MEA and reference screw electrode (" $R$ ") is depicted on the brain of a rat after the experiment and its surgical removal. Right graph: average electrode impedance (mean and standard deviation, $\mathrm{n}=8$ ) measured in vivo with three-day intervals. In chronic recordings, the electrode was capable of yielding signals comparable with the presented acute signals for approximately two weeks after array implantation. Note the impedance jump on day 16, coinciding with a decay in the responses (not shown)

The SEP recordings obtained with our array are comparable in their signal-to-noise ratios with previously published recordings with various electrode materials, such as platinum (Hayton et al., 1999), silver (Kalliomäki et al., 1998) and tungsten (Ureshi et al., 2004). Recordings are also comparable to previous studies with microelectrode arrays (Stett et al., 2003). In chronic recordings, the electrode was capable of capturing a biologically meaningful signal (comparable to signals in the acute experiment) for approximately two weeks after array implantation. However, after 16 days, the responses decayed due to a variety of mechanical and technical reasons. The signal amplitude decreased at the same time as the electrode impedance doubled (Fig. 6). Although no macroscopic scar formation was seen in the examination of the brain after the array was removed, this kind of increase in in vivo impedance is compatible with a thickening of the dura, a common finding in chronic experiments, and microscopic growth of non-conductive fibrous tissue around the electrode, shrinking the freely exposed surface area of the recording site.

Our current research is concentrating on improving biocompatibility issues, the array construction and implantation techniques in order to prolong the functional lifetime. The goals of the work include development of nanostructured electrode surfaces by utilizing ultra short pulsed laser deposition (USPLD) techniques or electrolytic deposition methods to improve the electrochemical functionality of electrodes as well as to incorporate functional coatings and/or biological compounds to polyimide layer to reduce the growth of scar tissue in the vicinity of array. 


\section{Biocompatibility testing}

Despite the very challenging microfabrication processes used in electrode fabrication, electrode failures due technical reasons (short-circuits, broken signal transmission lines etc.) are rare, and the stable, long-term functioning of neural implants is mainly determined by the tissue response to chronically implanted electrodes. A general immune activation of the brain in response to the presence of a foreign body implant has been commonly believed to be the main reason for signal deterioration of chronically implanted electrodes (Nicolelis et al., 2003; Edell et al., 1992; Schmidt et al., 1993). Biocompatibility aspects of neural implant materials will therefore be very crucial in the development of new generation chronic implants. In this section, we summarize some in vivo implantation and in vitro cell culture studies, concentrating particularly on these potential flexible thin film electrode materials that were already discussed in this chapter, i.e. $\mathrm{Pt}, \mathrm{Au}$, Ir, polyimide, SU-8, PDMS etc.

\subsection{In vivo implantation studies}

The tissue response to neural implant materials has been widely reported in the literature. Stensaas and Stensaas implanted 27 different materials, consisting of metals and insulators, into the cortices of rabbits. After 30 days, the histological examination revealed no adverse reaction in response to gold, platinum and tungsten (Stensaas \& Stensaas, 1978). Moreover, subdural implantations of two common insulators, parylene-C and polyimide (PI-2555), into the cerebral cortex of the cat evoked only minimal tissue reactions after a 16 week implantation period. All neurons situated beneath the implant site appeared to be normal. Tissue reactions to polyimide and parylene- $C$ were comparable to pure platinum (negative control) whereas $\mathrm{Ag}-\mathrm{AgCl}$ (positive control) had triggered chronic inflammatory reactions (Yuen et al., 1987). In another study, polyesterimide-coated gold wires implanted subdurally on rabbit cortex showed no evidence of toxicity. There was only slight gliosis, and there were no inflammatory reactions present at 16 weeks after implantation (Yuen \& Agnew, 1995). On the other hand, polyimide-platinum electrodes implanted to the rat scientic nerve for 3 months were demonstrated to induce a mild scar response and local inflammation reactions, though these were limited to a small area around the electrode (Lago et al., 2007). Unfortunately all artificial materials implanted in the CNS have an inconvenient tendency to induce significant glial scar tissue formation (Polikov et al., 2005). This gliotic scar tissue is attributable mainly to glial cells such as astrocytes and microglia and it poses one of the greatest challenges in the field of neural prosthetics. The formation of scar tissue can cause serious impairment of implant performance due to decreased local density of neurons and the formation of an encapsulation layer that increases electrode impedance and lowers the signal amplitudes. Astrocytes that account for 30-65\% of glial cell population in the CNS are able to secrete 8-10 nm diameter intermediate filaments of polymerized glial fibrillary acid protein (GFAP). When the electrode is implanted into the CNS, the astrocytes become activated and they transform into reactive phenotype which produces much larger size GFAP filaments and there is also enhanced cell proliferation and migration capacity. GFAP is the most commonly used astrocyte specific cell marker with which to assess the level of scar formation after electrode implantation. The brain slices of rats used in the chronic experiments are in cultured with anti-GFAP staining antibodies. GFAP- positive cells are counted around the implantation area of the cortex in order to estimate the extent of astrocyte activation and gliosis. In previous studies with probe-type electrodes, it has been 
shown that the astrocyte response to brain injury can be divided into two phases, the early response that occurs immediately after electrode implantation and the long-term chronic response. It has been reported that the number of astrocytes and microglia is significantly increased in the area surrounding the silicon probes (Szarowski et al., 2003; Turner et al., 1999) within a few hours after insertion. The extent of this early response is dependent on probe size, shape and surface roughness (Szarowski et al., 2003). The long-term response, starting approximately one week after electrode implantation (Norton et al., 1992), consists of a compact glial scar tissue formation surrounding the electrode and which ultimately isolates the microelectrodes from neurons/neural tissue elevating the impedance and causing signal deterioration (Nicolelis et al., 2003; Edell et al., 1992; Schmidt et al., 1993).

\subsection{In vitro cytotoxicity}

In vitro cytotoxicity tests play an important role in evaluating the biocompatibility properties of potential novel materials. The international standard "Biological evaluation of medical devices: tests for in vitro cytotoxicity" (ISO 10993-5) describes the test methods to assess the in vitro cytotoxicity of implant materials and medical devices. The mammalian cell line is selected according to the intended application. Cells are seeded in contact with a tested material and/or with an extract of a test material and different parameters are evaluated such as cell adherence, adhesion, proliferation, morphological changes and metabolism changes.

Kotzar et al. (2002) performed an in vitro cytotoxicity evaluation of a wide variety of materials used in microelectro-mechanical systems (MEMS) including Si, thermal oxide, ndoped polysilicon, $\mathrm{Si}_{3} \mathrm{~N}_{4}, \mathrm{Ti}, \mathrm{SU}-8$ and silicon carbide. Minimal cytotoxicity was demonstrated for these materials.

Polyimides have been shown to be non-cytotoxic in many in vitro studies (Richardson et al., 1993; Stieglitz et al., 2000). Stieglitz et al. (2000) studied the cytotoxicity of three commercial polyimide grades (Pyralin PI 2611, PI 2556, PI 2566, HD Microsystems) and reported excellent biocompatibility for PI 2611 and PI 2556 and good results for PI 2566. This last polyimide, since it is fluorinated, differs from the others with respect to its chemical structure. Furthermore, Lee et al. (2004b) reported that fibroblast cells attached, spread out and grew on polyimide surfaces in a corresponding manner to the behaviour of control cells growing on the surface of polystyrene. However the previously tested polyimides are mainly non-photosensitive. In a recent study, Sun et al. (2008) assessed the biocompatibility of a photosensitive polyimide for use in an implantable medical device. They concluded that the photosensitive polyimide (Fujifilm Durimide 7020) was also noncytotoxic and the fibroblast (L929) cell adhesion, morphology, and spreading was even enhanced on the photosensitive grade than one non-photosensitive grade (HD Microsystem PI-2611).

Figure 7 presents fibroblast cells (BHK-21) cultured on polyimide (Pyralin PI-2525, HD Microsystems $\mathrm{GmbH}$ ), high-density polyethylene (negative control) and latex rubber (positive control) after $24 \mathrm{~h}$ incubation period. Only a few cells are seen on cytotoxic latex rubber whereas the cell density on polyimide is even higher than on PE demonstrating the excellent biocompatibility of this polyimide grade. 

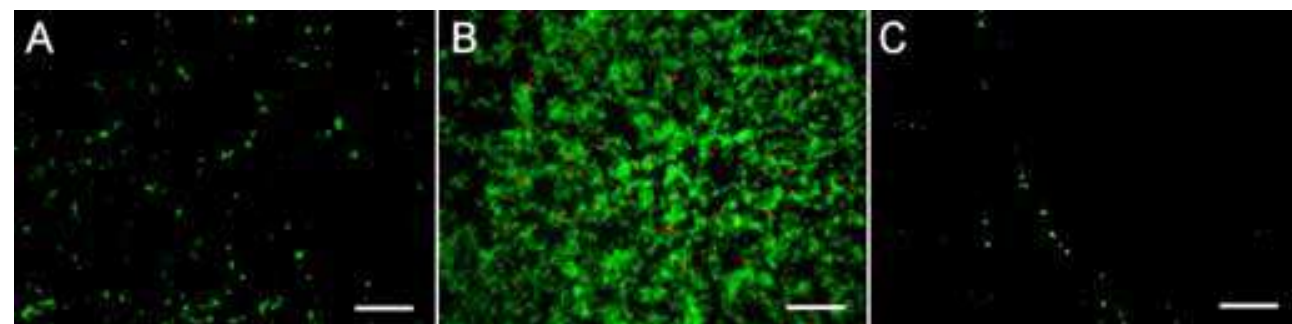

Fig. 7. Live/dead staining of BHK-21 fibroblast cells cultured on the surfaces of (A) polyethylene (negative control), (B) polyimide (C) latex rubber (positive control) after a 24 hour incubation period. Confocal laser microscope image, viable cells: green, dead cells: red, scale bar $=200 \mu \mathrm{m}$

The optimal electrode site should support neuronal cell attachment and growth. Thanawala et al. (2007) studied the biocompatibility of metal thin films in vitro cell culture studies. The results showed that iridium oxide and platinum thin films are biocompatible and non-toxic for neural cell (cortical rat neurons) growth. Furthermore, Pt films were reported to be superior to iridium oxide films in their ability to support cell attachment.

\section{Future trends and strategies to improve the long-term performance of implanted electrodes}

Surface modifications of materials intended for implantation are needed in order to improve the functionality and biocompatibility of implanted electrodes, i.e. to reduce the formation of the glial scar, prevent inflammatory reactions and extend the functional lifetime of the implanted devices, and this is an area in which there is intensive worldwide research. It must be noted that there are different requirements for different parts of a neural implant. Recording electrode sites should remain bare to achieve good signal output whereas encapsulation materials should be allowed to be covered by tissue cells like fibroblasts in order to allow them to co-exist in the human body. In this section, we will concentrate on future trends and strategies to improve the long-term performance of neural implants by dividing them into two categories: material science and bioactive molecule strategies.

\subsection{Material science strategies}

It is well-known that the there is an inverse relationship between electrode impedance and its surface area. Therefore, it is advantageous to develop microelectrodes with high nanoscale surface topography since in this way it will be possible to achieved high effective surface area without increasing the geometrical surface area. Electrodeposition of platinum (Pt black) is a classic technique which can increase surface roughness and lower electrode impedance (de Haro et al., 2002). Other common surface modification techniques used to increase nanoscale roughness are wet etching of gold and activating of iridium to form a nanoporous iridium oxide layer. Different etching and machining techniques (e.g. reactive ion etching, laser ablation etc.) can be also used to form different micro/nanostructures, e.g. grooves and wells onto the surface of the substrate upon which the electrode material can then be deposited using traditional thin film techniques. On the other hand, USPLD (Phipps, 2007; Eason, 2007) can be used both to deposit thin films and to create a nanostructured 
surface in a well-controlled and straightforward manner without the need for several process steps. An example of nanostructured Pt surface from our experiments is shown in Fig. 8. The size of the features is about $30 \mathrm{~nm}$ in this case. Furthermore, it is possible to combine micro/nanomachining using ultra short pulsed laser ablation and deposition to create well controlled and high quality surface textures like grooves, wells, holes etc.

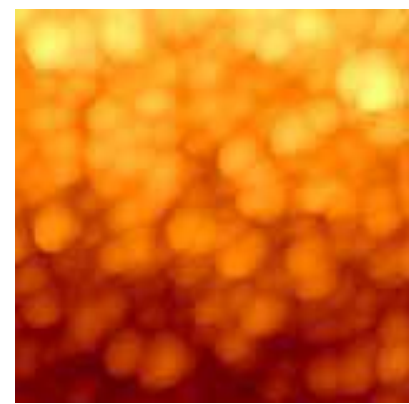

Fig. 8. AFM image of nanostructured Pt surface deposited using the USPLD technique. The average size of Pt particles is $30 \mathrm{~nm}$

It has been also shown that electrode surface morphology has a strong influence on neurocompatibility. Enhanced functions of neurons have been demonstrated on biomaterials structured at the nanoscale (Bayliss et al., 1999; Raffa et al., 2007). Raffa et al. (2007) used focused ion beam technology as a nanometric precision machining technique to modify the surface morphology of tungsten, and studied the effect of the nanofeatures on adherence and adhesion of PC12 neural cells. They concluded that the ability of PC12 cells to adhere to the surface is strongly linked to the dimensions of nanofeatures and the feature size of $25 \mathrm{~nm}$ is superior than $270 \mathrm{~nm}$ material. Positive interactions between neurons and nanostructured silicon surfaces with $10 \mathrm{~nm}$ pores have been also shown (Bayliss et al., 1999). However, there is one report of decreased astrocyte adhesion and increased extension of neuritis on nanoporous silicon surfaces (Moxon et al., 2004). Decreased adhesion, reduced proliferation and less long-term functional activation of astrocytes on carbon nanofiber materials (fiber diameter $60 \mathrm{~nm}$ ) compared to conventional carbon fibres (diameters in range of 125-200 nm) have also been demonstrated (McKenzie et al., 2004). These results provide evidence that nanoscale materials may have a promising future, i.e. they increase effective surface area of electrode and interact positively with neurons but at the same time they reduce the functions of astrocytes leading to decreased glial scar tissue formation.

As discussed before, conventional lithographic techniques can be combined with thin film techniques like evaporation, sputtering or electrodeposition. In spite of their widespread use, for example in the electronics industry, they have some shortcomings in electrode preparation compared to some novel techniques such as USPLD. In this study, we utilized ColdabTM USPLD configurations developed by Picodeon Ltd, Finland. This technique (Amberla et al., 2006) has several advantages in thin film preparation such as high adhesion, smooth or nanostructured surface topography and the possibility to deposit films or particles on heat sensitive substrates. Furthermore, different kinds of materials (polymers, metals or ceramics) can be used as a source to prepare single material films or composites, i.e. multilayer structures or homogeneous or graded composite films. High purity source 
materials available in a solid form can be utilized and transferred from the target to the sample in a stoichiometric manner. Due to the significant increase in power produced by picosecond pulsed lasers during recent years, this deposition technique has acquired commercial state, i.e. it can be used for deposition on large surfaces (in dimensions of ten centimetres), not just on small laboratory test samples. Thus USPLD technique holds an evident potential for neural electrode development.

The USPLD is a very effective method to convert a material so it can be deposited as a plasma, atom or molecular beam to produce bioinert, biocompatible, bioactive or bioresorbable films without generating extra heat on the sample surface (Eason, 2007). Therefore, the sample remains normally very close to room temperature and it is possible to deposit thin films on heat sensitive materials like polymers, which can be utilized in flexible electrodes or as a photoresist. Samples containing polymeric materials can be kept at low temperatures during the deposition and thus avoid hardening or flow during deposition. This leads to smooth high quality films and easy lift-off in the case of lithography. Since the target materials remain almost at room temperature, no water cooling is needed which is convenient since different target materials and dimensions can be utilized. Expensive target materials like $\mathrm{Pt}, \mathrm{Au}$, Ir or ITO can be used effectively and they remain free from contamination. Since one has many possible material choices, the material combinations can be optimized with respect to signal stability, biocompatibility, cell attachment, antibacterial properties etc. Enhanced surface properties can be achieved by including appropriate surface modifying layers: these can be organic compounds like collagen, fibronectin or even cells.

If USPLD is used in the creation of deposition electrodes, one important advantage compared to several other methods, is that the growing film does not contain microparticles or droplets, which would cause pinholes in the films. This is due to the fact that the laser ablation pulse is so short that the energy penetrates to only very shallow (tens of nanometers) surface layer which is effectively converted to plasma and the target surface remains smooth without any flows or deteriorations. The quality of the film becomes an important issue, for example in the case of insulator films for neural sensors. Based on our tests, these films do not seem to contain any microdefects which could lead to short circuiting especially in liquids. In addition to ceramic insulators like alumina $\left(\mathrm{Al}_{2} \mathrm{O}_{3}\right)$, polymers can be deposited with the same technique. The ultrasmoothness of deposited coatings might provide an additional benefit to avoid scar tissue formation, inflammation reactions or activation of glial cells.

\subsection{Strategies involving anti-inflammatory agents and bioactive molecules}

Several strategies are currently being studied to discover effective methods to minimize the immune response and inflammation around the neural implant as well as to encourage neural growth at electrode sites (Polikov et al., 2005; Zhong \& Bellamkonda, 2008). Antiinflammatory agents, such as dexamethasone (DEX) can be used to minimize the release of inflammatory mediators and to attenuate the formation of a fibrous capsule. DEX and other pharmaceutical agents can be administered in several way e.g. subcutaneous injection (Shain et al., 2003; Spataro et al., 2005) and the local release from electrode coatings of the drugs as incorporated agents (Zhong \& Bellamkonda, 2007; Kim \& Martin 2006). It is believed that the local delivery of DEX reduces the inflammatory tissue response and prevents the elevation in electrode impedance more effectively compared to peripheral 
injection since in the latter case there may be difficulties in the drugs crossing the bloodbrain barrier and chronic use of corticosteroids can evoke several side effects, such as myopathy and diabetes (Zhong \& Bellamkonda, 2007). Additionally, Si-based microelectrode arrays have been developed with integrated microfluidic drug delivery channels through which the bioactive molecule was released (Retterer et al., 2004; Rathnasingham et al., 2004). In addition, flexible multi-channel polyimide recording probes with incorporated small pores and wells that can be selectively filled with a dextran hydrogel and bioactive species such as nerve growth factor (NGF) (Rousche et al., 2001) as well as devices containing microfluidic channels for drug delivery (Metz et al., 2004) have been developed.

Several bioactive molecules are being investigated as potential binding molecules to promote the adherence and functions of neurons at the electrode site. Instead of using intact cell adhesion proteins such as collagen and fibronectin (Ignatius et al., 1998), new research efforts are concentrated on functionalizing the electrode surfaces with relevant protein sequences such as RGD, YIGSR and IKVAV (Polikov et al., 2005; Kam et al., 2002). It has been demonstrated that functionalized surfaces with these kinds of protein sequences can be used to support neuronal growth or repel glial growth. Furthermore, peptides can be deposited in patterns by using soft lithographic (Xia \& Whitesides, 1998) techniques intended to guide cellular outgrowth.

\section{Conclusion}

Modern microfabrication techniques offer great opportunities in the development of novel implantable neural interfaces for recording and stimulating purposes. Miniaturized electrode arrays with high-channel densities are now in common use in animal models, but their human counterparts are still mainly being investigated or at best undergoing clinical trials. Silicon has been the mostly utilized substrate material despite its rigidity, but recently there has been a growing interest toward polymeric implant materials that could be flexible enough to mimic biological tissue and to reduce adverse tissue reactions. Despite the very challenging microfabrication processes used in electrode fabrication, electrode failures due technical reasons are rare, and the stable, long-term functioning of neural implants is mainly determined by the tissue response to chronically implanted electrodes. Therefore, current investigations are now concentrating on the evaluation of the tissue-electrode interface aiming to improve the functionality and biocompatibility of implanted electrodes, i.e. to reduce the formation of the glial scar, prevent inflammatory reactions and extend the functional lifetime of the implanted microdevices. Further development of implantable neural electrodes promises to deliver novel options to acquire more detailed information of brain functions, to plan more precise surgical operations as well as improving the quality of life for many patients suffering pain or from loss of neural functions.

\section{Acknowlegdements}

This study was supported by the PhD-programme in Musculoskeletal Diseases and Biomaterials and the Otto A. Malm Foundation. The authors would like to thank the contribution of the following people: Prof. Heikki Tanila and Dr. Kaj Djupsund (in vivo experiments), Dr. Virpi Tiitu and Sanna Miettinen (cell culture studies), Dr. Markku Tiitta 
(EIS studies), Hannu Korhonen (sputter depositions) and Dr. Ewen MacDonald (language editing). The Microsensor Laboratory of the Savonia University of Applied Sciences is acknowledged for providing photolithographic and AFM imaging facilities. Picodeon Ltd is acknowledged for providing Coldab ${ }^{\mathrm{TM}}$ depositions.

\section{References}

Amberla, T.; Rekow, M.; Köngäs, J.; Asonen, H.; Salminen, T.; Viitanen, N.; Kulmala, M.; Vuoristo, P.; Pessa, M. \& Lappalainen, R. (2006). Pulsed laser deposition with a high average power fiber laser. Proceedings of 49th Annual Technical Conference (Society of Vacuum Coaters), pp. 79-82, Washington D.C., USA, April 22-27, 2006.

Armani, D.; Liu, C. \& Aluru, N. (1999). Re-configurable fluid circuits by PDMS elastomer micromachining. IEEE International Conference on Micro Electro Mechanical Systems, pp. 222-227, January 17-21, 1999.

Bayliss, S. C.; Buckberry, L. D.; Fletcher, I. \& Tobin, M. J. (1999). The culture of neurons on silicon. Sensors and Actuators A: Physical, Vol. 74, No. 1-3, (1999), pp. 139-142.

Bogner, E.; Dominizi, K.; Hagl, P.; Bertagnolli, E.; Wirth, M.; Gabor, F.; Brezna, W. \& Wanzenboeck, H. D. (2006). Bridging the gap-Biocompatibility of microelectronic materials. Acta Biomaterialia, Vol. 2, No. 2, (2006), pp. 229-237.

Boppart, S. A.; Wheeler, B. C. \& Wallace, C. S. (1992). A flexible perforated microelectrode array for extended neural recordings. IEEE Transactions on Biomedical Engineering, Vol. 39, No. 1, (1992), pp. 37-42.

Campbell, P. K.; Jones, K. E.; Huber, R. J.; Horch, K.W. \& Normann, R. A. (1991). A siliconbased, three-dimensional neural interface: manufacturing processes for an intracortical electrode array. IEEE Transactions on Biomedical Engineering, Vol. 38, No. 8, (1991), pp. 758-768.

Cheung, K. C. (2007). Implantable microscale neural interfaces. Biomedical Microdevices, Vol. 9, No. 6, (2007), pp. 923-938.

Cheung, K. C.; Renaud, P.; Tanila, H. \& Djupsund, K. (2007). Flexible polyimide microelectrode array for in vivo recordings and current source density analysis. Biosensors and Bioelectronics, Vol. 22, No. 8, (2007), pp. 1783-1790.

de Haro, C.; Mas, R.; Abadal, G.; Muñoz, J.; Perez-Murano, F. \& Domínguez, C. (2002). Electrochemical platinum coatings for improving performance of implantable microelectrode arrays. Biomaterials, Vol. 23, No. 23, (2002), pp. 4515-4521.

Eason, R. (2007). Pulsed Laser Deposition of Thin Films: Applications-Led Growth of Functional Materials, Wiley-Interscience, ISBN: 978-0-470-05211-2, New Jersey.

Edell, D. J.; Toi, V. V.; McNeil, V. M. \& Clark, L. D. (1992). Factors influencing the biocompatibility of insertable silicon microshafts in cerebral cortex. IEEE Transactions on Biomedical Engineering, Vol. 39, No. 6, (1992), pp. 635-643.

Geddes, L. A. \& Roeder, R. (2003). Criteria for the selection of materials for implanted electrodes. Annals of Biomedical Engineering, Vol. 31, No. 7, (2003), pp. 879-890.

González, C. \& Rodríguez, M. (1997). A flexible perforated microelectrode array probe for action potential recording in nerve and muscle tissues. Journal of Neuroscience Methods, Vol. 72, No. 2, (1997), pp. 189-195. 
Hayton, S. M.; Kriss, A. \& Muller, D. P. (1999). Comparison of the effects of four anaesthetic agents on somatosensory evoked potentials in the rat. Laboratory Animals, Vol. 33, No. 3, (1999), pp. 243-251.

Hollenberg, B. A.; Richards, C. D.; Richards, R.; Bahr, D. F. \& Rector, D. M. (2006). A MEMS fabricated flexible electrode array for recording surface field potentials. Journal of Neuroscience Methods, Vol. 153, No. 1, (2006), pp. 147-153.

Hosp, J.A.; Molina-Luna, K.; Hertler, B.; Atiemo, C.O.; Stett, A. \& Luft, A.R. (2008). Thin-film epidural microelectrode arrays for somatosensory and motor cortex mapping in rat. Journal of Neuroscience Methods, Vol. 172, No. 2, (2008), pp. 255-262.

Ignatius, M. J.; Sawhney, N.; Gupta, A.; Thibadeau, B. M.; Monteiro, O. R. \& Brown, I. G. (1998). Bioactive surface coatings for nanoscale instruments: effects on CNS neurons. Journal of Biomedical Materials Research, Vol. 40, No. 2, (1998), pp. 264-274.

Kalliomäki, J.; Luo, X.-L.; Yu, Y.-B. \& Schouenborg, J. (1998). Intrathecally applied morphine inhibits nociceptive $C$ fiber input to the primary somatosensory cortex (SI) of the rat. Pain, Vol. 77, No. 3, (1998), pp. 323-329.

Kam, L.; Shain, W.; Turner, J. N. \& Bizios, R. (2002). Selective adhesion of astrocytes to surfaces modified with immobilized peptides. Biomaterials, Vol. 23, No. 2, (2002), pp. 511-515.

Kim, D.-H. \& Martin, D. C. (2006). Sustained release of dexamethasone from hydrophilic matrices using PLGA nanoparticles for neural drug delivery. Biomaterials, Vol. 27, No. 15, (2006), pp. 3031-3037.

Kitzmiller, J.; Beversdorf, D. \& Hansford, D. (2006). Fabrication and testing of microelectrodes for small-field cortical surface recordings. Biomedical Microdevices, Vol. 8, No. 1, (2006), pp. 81-85.

Kotzar, G.; Freas, M.; Abel, P.; Fleischman, A.; Roy, S.; Zorman, C.; Moran, J. M. \& Melzak, J. (2002). Evaluation of MEMS materials of construction for implantable medical devices. Biomaterials, Vol. 23, No. 13, (2002), pp. 2737-2750.

Lago, N.; Yoshida, K.; Koch, K. P. \& Navarro, X. (2007). Assessment of biocompatibility of chronically implanted polyimide and platinum intrafascicular electrodes. IEEE Transactions on Biomedical Engineering, Vol. 54, No. 2, (2007), pp. 281-290.

Lee, K.; He, J.; Clement, R.; Massia, S. \& Kim, B. (2004). Biocompatible benzocyclobutene (BCB)-based neural implants with micro-fluidic channel. Biosensors and Bioelectronics, Vol. 20, No. 2, (2004), pp. 404-407, (a).

Lee, K.; Singh, A.; He, J.; Massia, S.; Kim, B. \& Raupp, G. (2004). Polyimide based neural implants with stiffness improvement. Sensors and Actuators B: Chemical, Vol. 102, No. 1, (2004), pp. 67-72, (b).

Mata, A.; Fleischman, A. J. \& Roy, S. (2005). Characterization of polydimethylsiloxane (PDMS) properties for biomedical micro/nanosystems. Biomedical Microdevices, Vol. 7, No. 4, (2005), pp. 281-293.

McKenzie, J. L.; Waid, M. C.; Shi, R. \& Webster, T. J. (2004). Decreased functions of astrocytes on carbon nanofiber materials. Biomaterials, Vol. 25, No. 7-8, (2004), pp. 1309-1317.

Mercanzini, A.; Cheung, K.; Buhl, D. L.; Boers, M.; Maillard, A.; Colin, P.; Bensadoun, J.-C.; Bertsch, A. \& Renaud, P. (2008). Demonstration of cortical recording using novel flexible polymer neural probes. Sensors and Actuators A: Physical, Vol. 143, No. 1, (2008), pp. 90-96. 
Metz, S.; Bertsch, A.; Bertrand, D. \& Renaud, P. (2004). Flexible polyimide probes with microelectrodes and embedded microfluidic channels for simultaneous drug delivery and multi-channel monitoring of bioelectric activity. Biosensors and Bioelectronics, Vol. 19, No. 10, (2004), pp. 1309-1318.

Molina-Luna, K.; Buitrago, M. M.; Hertler, B.; Schubring, M.; Haiss, F.; Nisch, W.; Schulz, J. B. \& Luft, A. R. (2007). Cortical stimulation mapping using epidurally implanted thin-film microelectrode arrays. Journal of Neuroscience Methods, Vol. 161, No. 1, (2007), pp. 118-125.

Moxon, K. A.; Kalkhoran, N. M.; Markert, M.; Sambito, M. A.; McKenzie, J. L. \& Webster, J. T. (2004). Nanostructured surface modification of ceramic-based microelectrodes to enhance biocompatibility for a direct brain-machine interface. IEEE Transactions on Biomedical Engineering, Vol. 51, No. 6, (2004), pp. 881-889

Myllymaa, S.; Myllymaa, K.; Korhonen, H.; Djupsund, K.; Tanila, H. \& Lappalainen, R. (2008). Development of flexible thin film microelectrode arrays for neural recordings. Proceedings of International Federation of Medical and Biological Engineering (IFMBE), pp. 286-289, Riga, Latvia, June 2008, Springer, Berlin, (a).

Myllymaa, S.; Myllymaa, K.; Korhonen, H.; Gureviciene, I.; Djupsund, K.; Tanila, H. \& Lappalainen, R. (2008). Development of flexible microelectrode arrays for recording cortical surface field potentials. Proceedings of IEEE Engineering in Medicine and Biology Society, pp. 3200-3203, Vancouver, British Columbia, Canada, August 2008, (b).

Myllymaa, S.; Myllymaa, K.; Korhonen, H.; Töyräs, J.; Jääskeläinen, J. E.; Djupsund, K.; Tanila, H. \& Lappalainen, R. (2009). Fabrication and testing of polyimide-based microelectrode arrays for cortical mapping of evoked potentials. Biosensors and Bioelectronics, Vol. 24, No. 10, (2009), pp. 3067-3072.

Nair, D. R.; Burgess, R.; McIntyre, C. C. \& Lüders, H. (2008). Chronic subdural electrodes in the management of epilepsy. Clinical Neurophysiology, Vol. 119, No. 1, (2008), pp. 1128.

Najafi, K. \& Wise, K. D. (1986). Implantable multielectrode array with on-chip signal processing. IEEE Journal of Solid-State Circuits, Vol. 21, No. 6, (1986), pp. 1035-1044.

Nicolelis, M. A. L.; Ghazanfar, A. A.; Faggin, B. M.; Votaw, S. \& Oliveira, L. M. O. (1997). Reconstructing the engram: simultaneous, multisite, many single neuron recordings. Neuron, Vol. 18, No. 4, (1997), pp. 529-537.

Nicolelis, M. A. L. ; Dimitrov, D.; Carmena, J. M.; Crist, R.; Lehew, G.; Kralik, J. D. \& Wise, S. P. (2003). Chronic, multisite, multielectrode recordings in macaque monkeys. Proceedings of the National Academy of Sciences, Vol. 100, No. 19, (2003), pp. 1104111046.

Norton, W. T.; Aquino, D. A.; Hozumi, I.; Chiu, F. C. \& Brosnan, C. F. (1992). Quantitative aspects of reactive gliosis: a review. Neurochemical research, Vol. 17, No. 9, (1992), pp. 877-885.

Owens, A. L.; Denison, T. J.; Versnel, H.; Rebbert, M.; Peckerar, M. \& Shamma, S. A. (1995). Multi-electrode array for measuring evoked potentials from surface of ferret primary auditory cortex. Journal of Neuroscience Methods, Vol. 58, No. 1-2, (1995), pp. 209-220.

Phipps, C. (2007). Laser Ablation and Its Applications, Springer, ISBN: 978-0-387-30452-6, New York. 
Polikov, V. S.; Tresco, P. A. \& Reichert, W. M. (2005). Response of brain tissue to chronically implanted neural electrodes. Journal of Neuroscience Methods, Vol. 148, No. 1, (2005), pp. 1-18.

Raffa, V.; Pensabene, V.; Menciassi, A. \& Dario, P. (2007). Design criteria of neuron/electrode interface. The focused ion beam technology as an analytical method to investigate the effect of electrode surface morphology on neurocompatibility. Biomedical Microdevices, Vol. 9, No. 3, (2007), pp. 371-383.

Rasche, D.; Ruppolt, M.; Stippich, C.; Unterberg, A. \& Tronnier, V. M. (2006). Motor cortex stimulation for long-term relief of chronic neuropathic pain: a 10 year experience. Pain, Vol. 121, No. 1-2, (2006), pp. 43-52.

Rathnasingham, R.; Kipke, D. R.; Bledsoe, S. C., Jr. \& McLaren, J. D. (2004). Characterization of implantable microfabricated fluid delivery devices. IEEE Transactions on Biomedical Engineering, Vol. 51, No. 1, (2004), pp. 138-145.

Retterer, S. T.; Smith, K. L.; Bjornsson, C. S.; Neeves, K. B.; Spence, A. J. H.; Turner, J. N.; Shain, W. \& Isaacson, M. S. (2004). Model neural prostheses with integrated microfluidics: a potential intervention strategy for controlling reactive cell and tissue responses. IEEE Transactions on Biomedical Engineering, Vol. 51, No. 11, (2004), pp. 2063-2073.

Richardson, R. R.; Miller, J. A. \& Reichert, W. M. (1993). Polyimides as biomaterials: preliminary biocompatibility testing. Biomaterials, Vol. 14, No. 8, (1993), pp. 627-635.

Rodríguez, F. J.; Ceballos, D.; Schüttler, M.; Valero, A.; Valderrama, E.; Stieglitz, T. \& Navarro, X. (2000). Polyimide cuff electrodes for peripheral nerve stimulation. Journal of Neuroscience Methods, Vol. 98, No. 2, (2000), pp. 105-118.

Rousche, P. J.; Pellinen, D. S.; Pivin, D. P. Jr.; Williams, J. C.; Vetter, R. J.; \& Kipke, D. R. (2001). Flexible polyimide-based intracortical electrode arrays with bioactive capability. IEEE Transactions on Biomedical Engineering, Vol. 48, No. 3, (2001), pp. 361-371.

Schmidt, S.; Horch, K. \& Normann, R. (1993). Biocompatibility of silicon-based electrode arrays implanted in feline cortical tissue. Journal of Biomedical Materials Research, Vol. 27, No. 11, (1993), pp. 1393-1399.

Selvakumaran, J.; Keddie, J. L.; Ewins, D. J. \& Hughes, M. P. (2008). Protein adsorption on materials for recording sites on implantable microelectrodes. Journal of Materials Science: Materials in Medicine, Vol. 19, No. 1, (2008), pp. 143-151.

Seo, J.-M.; Kim, S. J.; Chung, H.; Kim, E. T.; Yu, H. G. \& Yu, Y. S. (2004). Biocompatibility of polyimide microelectrode array for retinal stimulation. Materials Science and Engineering: C, Vol. 24, No. 1-2, (2004), pp. 185-189.

Shain, W.; Spataro, L.; Dilgen, J.; Haverstick, K.; Retterer, S.; Isaacson, M.; Saltzman, M. \& Turner, J. N. (2003). Controlling cellular reactive responses around neural prosthetic devices using peripheral and local intervention strategies. IEEE transactions on neural systems and rehabilitation engineering, Vol. 11, No. 2, (2003), pp. 186-188.

Spataro, L.; Dilgen, J.; Retterer, S.; Spence, A. J.; Isaacson, M.; Turner, J. N. \& Shain, W. (2005). Dexamethasone treatment reduces astroglia responses to inserted neuroprosthetic devices in rat neocortex. Experimental neurology, Vol. 194, No. 2, (2005), pp. 289-300. 
Spence, A. J.; Neeves, K. B.; Murphy, D.; Sponberg, S.; Land, B. R.; Hoy, R. R. \& Isaacson, M. S. (2007). Flexible multielectrodes can resolve multiple muscles in an insect appendage. Journal of Neuroscience Methods, Vol. 159, No. 1, (2007), pp. 116-124.

Stensaas, S. S. \& Stensaas, L. J. (1978). Histopathological evaluation of materials implanted in the cerebral cortex. Acta Neuropathologica, Vol. 41, No. 2, (1978), pp. 145-155.

Stett, A.; Egert, U.; Guenther, E.; Hofmann, F.; Meyer, T.; Nisch, W. \& Haemmerle, H. (2003). Biological application of microelectrode arrays in drug discovery and basic research. Analytical and Bioanalytical Chemistry, Vol. 377, No. 3, (2003), pp. 486-495.

Stieglitz, T.; Beutel, H. \& Meyer, J.-U. (1997). A flexible, light-weight multichannel sieve electrode with integrated cables for interfacing regenerating peripheral nerves. Sensors and Actuators A: Physical, Vol. 60, No. 1-3, (1997), pp. 240-243.

Stieglitz, T.; Beutel, H.; Schuettler, M. \& Meyer, J.-U. (2000). Micromachined, polyimidebased devices for flexible neural interfaces. Biomedical Microdevices, Vol. 2, No. 4, (2000), pp. 283-294.

Stieglitz, T. (2001). Flexible biomedical microdevices with double-sided electrode arrangements for neural applications. Sensors and Actuators A: Physical, Vol. 90, No. 3, (2001), pp. 203-211.

Strumwasser, F. (1958). Long-term recording' from single neurons in brain of unrestrained mammals. Science, Vol. 127, No. 3296, (1958), pp. 469-470.

Sun, Y.; Lacour, S. P.; Brooks, R. A.; Rushton, N.; Fawcett, J. \& Cameron, R. E. (2008). Assessment of the biocompatibility of photosensitive polyimide for implantable medical device use. Journal of Biomedical Materials Research Part A, (2008).

Szarowski, D. H.; Andersen, M. D.; Retterer, S.; Spence, A. J.; Isaacson, M.; Craighead, H. G.; Turner, J. N. \& Shain, W. (2003). Brain responses to micro-machined silicon devices. Brain Research, Vol. 983, No. 1-2, (2003), pp. 23-35.

Takahashi, H.; Ejiri, T.; Nakao, M.; Nakamura, N.; Kaga, K. \& Herve, T. (2003). Microelectrode array on folding polyimide ribbon for epidural mapping of functional evoked potentials. IEEE Transactions on Biomedical Engineering, Vol. 50, No. 4, (2003), pp. 510-516.

Takeuchi, S.; Ziegler, D.; Yoshida, Y.; Mabuchi, K. \& Suzuki, T. (2005). Parylene flexible neural probes integrated with microfluidic channels. Lab on a Chip, Vol. 5, (2005), pp. 519-523.

Thanawala, S.; Palyvoda, O.; Georgiev, D. G.; Khan, S. P.; Al-Homoudi, I. A.; Newaz, G. \& Auner, G. (2007). A neural cell culture study on thin film electrode materials. Journal of Materials Science: Materials in Medicine, Vol. 18, No. 9, (2007), pp. 17451752.

Turner, J. N.; Shain, W.; Szarowski, D. H.; Andersen, M.; Martins, S.; Isaacson, M. \& Craighead, H. (1999). Cerebral astrocyte response to micromachined silicon implants. Experimental neurology, Vol. 156, No. 1, (1999), pp. 33-49.

Ureshi, M.; Matsuura, T. \& Kanno, I. (2004). Stimulus frequency dependence of the linear relationship between local cerebral blood flow and field potential evoked by activation of rat somatosensory cortex. Neuroscience Research, Vol. 48, No. 2, (2004), pp. 147-153.

Wennberg, A. (1994). Neurotoxic effects of selected metals. Scandinavian journal of work, environment $\mathcal{E}$ health, Vol. 20 Spec No, (1994), pp. 65-71. 
Williams, J. C.; Rennaker, R. L. \& Kipke, D. R. (1999). Long-term neural recording characteristics of wire microelectrode arrays implanted in cerebral cortex. Brain Research Protocols, Vol. 4, No. 3, (1999), pp. 303-313.

Wise, K. D. (2005). Silicon microsystems for neuroscience and neural prostheses. IEEE engineering in medicine and biology magazine: the quarterly magazine of the Engineering in Medicine \& Biology Society, Vol. 24, No. 5, (2005), pp. 22-29.

Xia, Y. \& Whitesides, G. M. (1998). Soft lithography. Annual Review of Materials Science, Vol. 28, No. 1, (1998), pp. 153-184.

Yeager, J.D.; Phillips, D.J.; Rector, D.M. \& Bahr, D.F. (2008). Characterization of flexible ECoG electrode arrays for chronic recording in awake rats. Journal of Neuroscience Methods, Vol. 173, No. 2, (2008), pp. 279-285.

Yuen, T. G.; Agnew, W. F. \& Bullara, L. A. (1987). Tissue response to potential neuroprosthetic materials implanted subdurally. Biomaterials, Vol. 8, No. 2, (1987), pp. 138-141.

Yuen, T. G. \& Agnew, W. F. (1995). Histological evaluation of polyesterimide-insulated gold wires in brain. Biomaterials, Vol. 16, No. 12, (1995), pp. 951-956.

Zhong, Y. \& Bellamkonda, R. V. (2007). Dexamethasone-coated neural probes elicit attenuated inflammatory response and neuronal loss compared to uncoated neural probes. Brain Research, Vol. 1148, No. 15-27, (2007), pp. 15-27.

Zhong, Y. \& Bellamkonda, R. V. (2008). Biomaterials for the central nervous system. Journal of the Royal Society, Interface / the Royal Society, Vol. 5, No. 26, (2008), pp. 957-975. 


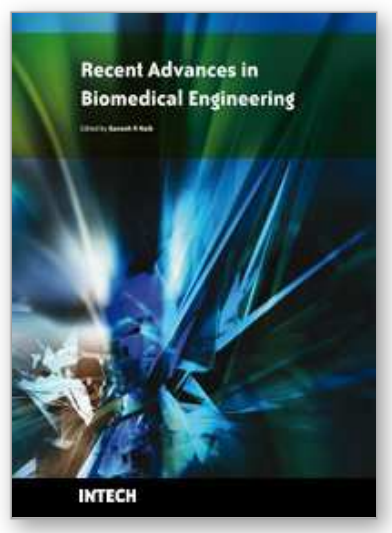

\author{
Recent Advances in Biomedical Engineering \\ Edited by Ganesh R Naik
}

ISBN 978-953-307-004-9

Hard cover, 660 pages

Publisher InTech

Published online 01, October, 2009

Published in print edition October, 2009

The field of biomedical engineering has expanded markedly in the past ten years. This growth is supported by advances in biological science, which have created new opportunities for development of tools for diagnosis and therapy for human disease. The discipline focuses both on development of new biomaterials, analytical methodologies and on the application of concepts drawn from engineering, computing, mathematics, chemical and physical sciences to advance biomedical knowledge while improving the effectiveness and delivery of clinical medicine. Biomedical engineering now encompasses a range of fields of specialization including bioinstrumentation, bioimaging, biomechanics, biomaterials, and biomolecular engineering. Biomedical engineering covers recent advances in the growing field of biomedical technology, instrumentation, and administration. Contributions focus on theoretical and practical problems associated with the development of medical technology; the introduction of new engineering methods into public health; hospitals and patient care; the improvement of diagnosis and therapy; and biomedical information storage and retrieval. The book is directed at engineering students in their final year of undergraduate studies or in their graduate studies. Most undergraduate students majoring in biomedical engineering are faced with a decision, early in their program of study, regarding the field in which they would like to specialize. Each chosen specialty has a specific set of course requirements and is supplemented by wise selection of elective and supporting coursework. Also, many young students of biomedical engineering use independent research projects as a source of inspiration and preparation but have difficulty identifying research areas that are right for them. Therefore, a second goal of this book is to link knowledge of basic science and engineering to fields of specialization and current research. The editor would like to thank the authors, who have committed so much effort to the publication of this work.

\title{
How to reference
}

In order to correctly reference this scholarly work, feel free to copy and paste the following:

Sami Myllymaa, Katja Myllymaa and Reijo Lappalainen (2009). Flexible Implantable Thin Film Neural Electrodes, Recent Advances in Biomedical Engineering, Ganesh R Naik (Ed.), ISBN: 978-953-307-004-9, InTech, Available from: http://www.intechopen.com/books/recent-advances-in-biomedical-engineering/flexibleimplantable-thin-film-neural-electrodes

\section{INTECH}

open science | open minds

\section{InTech Europe}

University Campus STeP Ri

Slavka Krautzeka 83/A

\section{InTech China}

Unit 405, Office Block, Hotel Equatorial Shanghai

No.65, Yan An Road (West), Shanghai, 200040, China 
51000 Rijeka, Croatia

Phone: +385 (51) 770447

Fax: +385 (51) 686166

www.intechopen.com
中国上海市延安西路65号上海国际贵都大饭店办公楼405单元

Phone: +86-21-62489820

Fax: $+86-21-62489821$ 
(C) 2009 The Author(s). Licensee IntechOpen. This chapter is distributed under the terms of the Creative Commons Attribution-NonCommercial-ShareAlike-3.0 License, which permits use, distribution and reproduction for non-commercial purposes, provided the original is properly cited and derivative works building on this content are distributed under the same license. 